\title{
Thawed Cryopreserved Synovial Mesenchymal Stem Cells Show Comparable Effects to Cultured Cells in the Inhibition of Osteoarthritis Progression in Rats
}

\author{
Kiyotaka Horiuchi \\ Tokyo Ika Shika Daigaku \\ Nobutake Ozeki \\ Tokyo Ika Shika Daigaku \\ Kentaro Endo \\ Tokyo Ika Shika Daigaku \\ Mitsuru Mizuno \\ Tokyo Ika Shika Daigaku \\ Hisako Katano \\ Tokyo Ika Shika Daigaku \\ Masako Akiyama \\ Tokyo Ika Shika Daigaku \\ Kunikazu Tsuji \\ M.D.,Ph.D.
}

\section{Hideyuki Koga}

Tokyo Ika Shika Daigaku

Ichiro Sekiya ( $\sim$ sekiya.arm@tmd.ac.jp)

Tokyo Medical and Dental University https://orcid.org/0000-0002-6331-722X

\section{Research}

Keywords: mesenchymal stem cell, synovium, cryopreservation, cultured MSCs, thawed MSCs, osteoarthritis

Posted Date: August 28th, 2020

DOl: https://doi.org/10.21203/rs.3.rs-63516/v1

License: (c) (1) This work is licensed under a Creative Commons Attribution 4.0 International License. Read Full License 


\section{Abstract}

\section{Background}

Intra-articular injections of mesenchymal stem cells (MSCs) can inhibit the progression of osteoarthritis (OA) in animal studies. Previous reports have used cultured MSCs, but the ability to use thawed cryopreserved MSC stocks would be highly advantageous. Our purpose was to elucidate whether thawed cryopreserved MSCs show comparable inhibitory effects on OA progression in rats to those obtained with cultured MSCs.

\section{Methods}

Cultured rat synovial MSCs or thawed MSCs were compared for in vitro viability and properties. The activity of synovial MSCs derived from rats expressing luciferase was compared by the luminescence intensity both in vitro and in vivo. The inhibitory effect of cultured MSCs on OA progression was evaluated by injecting PBS and cultured MSCs into the right and left knees, respectively, of the same individual meniscectomized rats. A similar test evaluated cryopreservation fluid (95\% FBS with 5\% DMSO; termed the 95\% FBS group) versus thawed MSCs. Cartilage degeneration was assessed at 4 and 8 weeks using gross finding and histological scores. The results were used to set the primary outcome and sample size. Cultured MSCs were then injected into one knee and thawed MSCs into the contralateral knee of the same individual to compare their effects.

\section{Results}

Cultured MSCs and MSCs thawed after cryopreservation in 95\% FBS with 5\% DMSO had comparable in vitro viability, colony formation, and chondrogenic potential. The luminescence intensity was comparable between the two MSC preparations. In the rat OA model, the gross findings and histological scores for tibial cartilage did not differ at four weeks but were significantly lower in the cultured MSC group than in the PBS group and significantly lower in the thawed MSC group than in the $95 \%$ FBS group at eight weeks. These results established the tibial cartilage histological score at eight weeks as the primary outcome and a sample size of nine for comparing cultured versus thawed MSCs. The tibial cartilage histological scores did not differ significantly at eight weeks after injection of cultured and thawed MSCs into the opposite knees of the same individuals.

\section{Conclusions}

Thawed MSCs showed comparable inhibitory effects on OA progression to cultured MSCs.

\section{Background}

Osteoarthritis (OA) is the most common joint disease in the world [1] and a leading cause of disability worldwide. Knee OA is the largest cause of locomotion disorders in older adults [2], and the prevalence of this disease is anticipated to increase in the coming decades [3]. Currently, no consensus exists regarding 
disease-modifying therapies that address structural abnormalities of the knee or other joints affected by OA.

Mesenchymal stem cells (MSCs) are a promising source for cell therapies. In recent years, clinical reports on the effectiveness of intra-articular injections of MSCs as a treatment for knee OA are increasing. A systematic review showed that intra-articular injections of MSCs improved knee pain but did not fully demonstrate that the injections inhibited the progression of OA [4]. Many clinical case studies have used cultured MSCs [5-7], but some studies have used MSCs thawed after cryopreservation [8]. The latter MSC source is more useful because the timing of the injection can be easily adjusted.

A growing number of papers have compared cultured and thawed MSCs for their properties as MSCs and their therapeutic effects on some diseases. While several in vitro studies have shown that thawed MSCs were inferior to cultured MSCs in terms of viability [9], metabolic activity [10], proliferation [11] and differentiation potential [10,12], other studies have found no differences [13-17]. No consensus has yet been reached in in vitro studies, but some in vivo studies have reported similar immunosuppressive effects between cultured and thawed MSCs [17-19]. However, similar results for disease models including $\mathrm{OA}$ are lacking, and an inhibitory effect of thawed MSCs on OA progression has not been described to date, though injections of cultured MSCs have been shown to inhibit the progression of osteoarthritis (OA) in animal studies [20, 21].

The primary purpose of the present study was to elucidate whether thawed MSCs would have a comparable inhibitory effect on OA progression to that seen with cultured MSCs. We first investigated the effects of cryopreservation on the viability and properties of rat synovial MSCs. We then validated the inhibitory effect of cultured versus thawed MSCs on OA progression in a meniscectomized rat model. These results established the primary outcome and sample size for the final experiments, in which we injected cultured and thawed MSCs into the opposite knees of the same individuals to directly compare their effects.

\section{Methods}

\section{Rat synovial MSCs}

All animal care and experiments were conducted in accordance with the institutional guidelines of the Animal Committee of Tokyo Medical and Dental University. Wildtype female Lewis rats (10 weeks of age, weighing 180-200 g) were purchased from Sankyo Labo Service Corporation, Inc. (Tokyo, Japan) ( $\mathrm{n}=$ 40). Luciferase-expressing transgenic rats [22] were also used for in vitro and vivo imaging $(n=4)$. The rats were kept in an environmentally controlled animal facility under a $12 \mathrm{~h}$ light/dark cycle with food and water ad libitum. Synovium was harvested from the rats' infrapatellar fat pads. The synovium was minced and digested with collagenase (Sigma, St. Louis, MO, USA) for $3 \mathrm{~h}$. Synovial nucleated cells were cultured for 7-10 days in a-minimum essential medium (a-MEM; Invitrogen, Carlsbad, CA, USA), 10\% fetal 
bovine serum (FBS; Invitrogen), and $1 \%$ antibiotic-antimycotic (Invitrogen) at $37^{\circ} \mathrm{C}$ under $5 \% \mathrm{CO}_{2}$. The resulting culture was collected and used as synovial MSCs $[20,23,24]$.

\section{Preparation of cultured and thawed cryopreserved MSCs}

Cells at passage 3-4 were cultured for one week and then trypsinized. The cultured MSCs were prepared by resuspending in PBS at $1 \times 10^{6}$ cells $/ \mathrm{mL}$ for in vitro studies or $20 \times 10^{6}$ cells $/ \mathrm{mL}$ for transplantation. The cryopreserved MSCs were prepared by resuspending the cells containing 95\% FBS and 5\% dimethyl sulfoxide (DMSO; Wako, Tokyo, Japan) at $1 \times 10^{6}$ cells $/ \mathrm{mL}$, transferring the tubes of cells to a bio freezing vessel (Bicell, Japan Freezer, Tokyo, Japan), placing the vessel in a freezer at $-80^{\circ} \mathrm{C}$ overnight, and storing at $-150^{\circ} \mathrm{C}$ for 6 days. The tubes were removed from the freezing vessel and the frozen cells were thawed using a cell-thawing device (ThawSTAR, Astero Bio, Menlo Park CA, USA). As a negative control for in vitro studies, the cells were also frozen in 100\% FBS [25].

\section{Viability}

Cell viability was assessed using the trypan blue exclusion test and calculated by dividing the total number of live cells counted post-thaw by the number of cells originally frozen in the tube. Cellular dehydrogenase activity was tested by reacting the cells with the working solution for 30 min at $37^{\circ} \mathrm{C}$ and quantified by a WST-8 assay (Dojindo, Kumamoto, Japan). The cell supernatant before and after preservation was also reacted at room temperature and assayed for lactate dehydrogenase (LDH) activity (Dojindo) by measuring the absorbance with a plate reader (Infinite M200; Tecan, Männedorf, Switzerland).

\section{Colony formation assay}

A $0.5 \mu \mathrm{L}$ volume of cell suspension (containing 500 cells, including living and dead cells) was plated in twelve $60 \mathrm{~cm}^{2}$ dishes and the cells were cultured for 14 days. Six dishes (dishes A, B, C, D, E, and F) were stained with crystal violet to count the total numbers of cell colonies. Colonies less than $2 \mathrm{~mm}$ in diameter were ignored. The cells were harvested from the other 6 dishes (dishes $G, H, I, J, K$, and $L$ ) to count the cell numbers per dish with a hemocytometer. The cell number per colony was calculated based on the cell number from dish $A$ divided by the colony number from dish $\mathrm{G}$, and this calculation was repeated for the remaining pairs of dishes (i.e., $B$ and $H, C$ and $I, D$ and $J, E$ and $K$, and $F$ and $L$ ). The mean and standard deviation were then determined for cell number per colony [26].

\section{Chondrogenesis}

A $250 \mu \mathrm{L}$ volume of cell suspension (containing $2.5 \times 10^{5}$ cells, including both living and dead cells) was added to six $15 \mathrm{~mL}$ tubes (Falcon) containing a chondrogenic induction medium consisting of Dulbecco's Modified Eagle Medium (DMEM; Thermo Fisher Scientific), $10 \mathrm{ng} / \mathrm{mL}$ transforming growth factor- $\beta 3$ (TGF- $\beta 3$, Miltenyi Biotec, Bergisch Gladbach, Germany), $500 \mathrm{ng} / \mathrm{mL}$ bone morphogenetic protein 2 (BMP2, Med- tronic, Minneapolis, MN, USA), $40 \mu \mathrm{g} / \mathrm{mL}$ proline (Sigma), $100 \mathrm{nM}$ dexamethasone, $100 \mu \mathrm{g} / \mathrm{mL}$ 
pyruvate (Sigma), $1 \%$ antibiotic-antimycotic, $50 \mu \mathrm{g} / \mathrm{mL}$ ascorbate-2-phosphate, and $1 \%$ ITS+ Premix (Becton Dickinson, San Jose, CA, USA). The cells were centrifuged at $450 \times \mathrm{g}$ for $10 \mathrm{~min}$ to form cell pellets, which were cultured for 21 days. The cultured cell pellets were photographed and weighed with a semi micro balance (CPA225D, Sartorius, Gottingen, Germany). The pellets were cut into $5 \mu \mathrm{m}$ sections and stained with safranin $\mathrm{O}$ and toluidine blue.

\section{Flow cytometry}

Rat synovial MSCs at passage 3 were detached by treatment with TrypLE (Thermo Fisher Scientific, MA, USA) for $10 \mathrm{~min}$ and used for surface marker analysis. The cell fluorescence and percentage of antigenpositive cells were evaluated with a FACSVerse instrument (BD Biosciences). CD90-PE-Cy7 (eBioscience, San Diego, CA, USA), CD44-PE (eBioscience), CD105-APC (Novus Biologicals, Littleton, CO, USA), CD45FITC (BD Pharmigen, San Jose, CA, USA) and CD34-PerCP-Cy5.5 (Novus Biologicals) antibodies were used. Cells were incubated with conjugated antibodies at $4{ }^{\circ} \mathrm{C}$ for 1 hour in the dark. Isotype controls were prepared as negative controls.

\section{Rat meniscectomized OA model}

Rats were anesthetized by isoflurane inhalation. Both the right and left knee joints received surgery. After a medial parapatellar incision and lateral dislocation of the patellar tendon, the medial meniscus was exposed. The anterior insertional ligament of the medial meniscus was transected to dislocate the medial meniscus anteriorly, and the medial meniscus was resected at the level of the medial collateral ligament $[22,27]$. The wound was closed in layers. After the surgery, the rats were allowed to walk freely in their cages.

\section{Bioluminescence imaging}

Synovial MSCs derived from luciferase-expressing transgenic rats ( $\mathrm{Luc}^{+} \mathrm{MSCs}$ ) were used. Cultured and thawed MSCs were plated into 96 -well plate at the density of $10^{3}, 10^{4}, 10^{5}$, and $10^{6}$ cells/well. D-luciferin potassium salt $(200 \mu \mathrm{g} / \mathrm{ml}$, ab143655, abcam, Cambridge, UK) was added to each well and the luminescence intensity was quantified using IVIS Lumina XRMS series III instrument (SPI, Tokyo, Japan). A sample containing $1 \times 10^{6}$ cultured and thawed Luc ${ }^{+}$MSCs were injected two months after the surgery. D-luciferin $(20 \mathrm{mg} / \mathrm{mL}, 50 \mu \mathrm{L})$ was injected into the knees at 1, 4, and 7 days after the transplantation, and photons were detected with the IVIS instrument $(n=4)$. The luminescence intensity was quantified as photon flux in units of photons per seconds in the region of each knee.

\section{Validation of the inhibitory effect of cultured and thawed MSCs on OA progression}

PBS was injected into one knee (PBS group) and $1 \times 10^{6}$ cultured MSCs suspended in PBS were injected into contralateral knee (Cultured group) every week beginning two weeks after the surgery $(n=12)$. In another group of rats, $95 \%$ FBS with 5\% DMSO was injected into one knee (95\%FBS group) and $1 \times 10^{6}$ 
thawed MSCs (suspended in 95\% FBS with 5\% DMSO with no compensation for viability) were injected into contralateral knee (Thawed group) every week beginning two weeks after the surgery $(n=12)$.

\section{Direct comparison between cultured MSCs and thawed MSC}

We injected $1 \times 10^{6}$ cultured MSCs suspended in PBS into the left and right sides of one knee (Cultured group) and $1 \times 10^{6}$ thawed MSCs (suspended in 95\% FBS with 5\% DMSO with no compensation for viability) into the sides of the contralateral knee (Thawed group) every week beginning two weeks after the surgery. All knees were evaluated at eight weeks $(n=9)$.

\section{Evaluations of cartilage degeneration}

Both the tibial and femoral condyles were removed separately and evaluated by India ink staining for macroscopic observation. Histological examinations were conducted by fixing both tibial and femoral cartilage in $10 \%$ formalin neutral buffer solution for 2 days and decalcifying with $20 \%$ ethylenediaminetetraacetic acid (EDTA; Wako, Tokyo, Japan) for 2 weeks, followed by paraffin wax embedding. The specimens of both medial condyles were sectioned in the sagittal plane at $5 \mu \mathrm{m}$ and stained with safranin $\mathrm{O}$ and fast green. Cartilage degeneration was evaluated using a modified "gross finding score" (Table 1)[27] and the Osteoarthritis Research Society International (OARSI) scoring system for histology [28]. Three different researchers independently scored the sections in a blinded manner and the median value was selected. 


\section{Table 1 Gross finding score: macroscopic cartilage scoring (0-6)}

\section{Grade Findings}

$0 \quad$ Intact articular surface

$1 \quad$ Fibrillation $(<0.5 \mathrm{~mm})$

$2 \quad$ Fibrillation $(\geq 0.5 \mathrm{~mm})$

$3 \quad$ Width of erosion area $(<0.5 \mathrm{~mm})$

$4 \quad$ Width of erosion area $(\geq 0.5 \mathrm{~mm},<1 \mathrm{~mm})$

$5 \quad$ Width of erosion area $(\geq 1 \mathrm{~mm},<1.5 \mathrm{~mm})$

$6 \quad$ Width of erosion area $(\geq 1.5 \mathrm{~mm},<2 \mathrm{~mm})$

Both the medial tibial and femoral condyle were evaluated separately, and the higher point value was selected.

\section{Statistical analysis}

Statistical analysis was performed with the Graph-Pad Prism 6 (GraphPad Software, CA, USA). For multiple comparisons, data were analyzed using repeated measures one-way ANOVA followed by Tukey's multiple comparisons or Kruskal-Wallis test followed by Dunn's multiple comparisons. Comparisons between the matched pairs were analyzed using the Wilcoxon's signed rank test. A P value of $<0.05$ was considered statistically significant. Before comparing the cultured and thawed groups directly, we calculated the sample size with a significance level of $5 \%$ and a power of $80 \%$ based on the OARSI histological score in tibial cartilage between the PBS-injected and the cultured MSC-injected knees. Data were expressed as mean \pm standard deviation. The methods of statistical analysis are described in each of the figure legends.

\section{Results}


Synovial MSCs thawed after cryopreservation in 95\% FBS with 5\% DMSO or 100\% FBS were compared with MSCs without cryopreservation (Fig. 1A). In vitro viability was not significantly different in MSCs thawed after cryopreservation in 95\% FBS with 5\% DMSO versus cultured MSCs (Fig. 1B), but cellular dehydrogenase activity and lactate dehydrogenase activity were significantly lower in the thawed MSCs as well as in MSCs thawed after cryopreservation in 100\% FBS (Fig. 1 C, and D). Colony formation of MSCs at passage 3 (Fig. 1E), determined as colony number per dish, cell number per dish, and cell number per colony, were not significantly different in thawed MSCs versus cultured MSCs (Fig. 1F, G, and H). MSCs thawed after cryopreservation in 100\% FBS formed very few cell colonies, whereas MSCs thawed after cryopreservation in 95\% FBS with 5\% DMSO formed similar cartilage pellets to those formed by cultured MSCs (Fig. 1I), and no significant difference was found for cartilage pellet weight (Fig. 1J). Sufficient numbers of thawed MSCs could not be prepared for pellet culture. Surface antigens in all three groups were consistent with the MSC pattern (Fig. 1K).

\section{Cell activity evaluated by luminescence intensity}

The activity of cultured and thawed MSCs was compared by the luminescence intensity of MSCs expressing luciferase (Fig. 2A). The luminescence intensity in both groups increased as the number of cells increased, but no difference was detected between the groups (Fig. 2B). The two groups of MSCs were then injected into the knees of rats in the OA model and their cellular activities in vivo were compared (Fig. 2C). The luminescence intensity decreased similarly in both groups after 4 days and further decreased after 7 days, with no difference between the two groups (Fig. 2D).

\section{Inhibitory effect of cultured versus thawed MSCs on OA progression in rats.}

PBS was injected into one knee and cultured MSCs were injected into the contralateral knee in one group of OA model rats. In another group, 95\% FBS with 5\% DMSO was injected into one knee and thawed MSCs were injected into the contralateral knee. The knee cartilage was then assessed to compare the left and right sides of the same individual (Fig. 3A). No macroscopic or histological differences were noted between the PBS and cultured MSC knees or between the 95\% FBS and thawed MSC knees at 4 weeks (Supplementary Figure 1, 2). At 8 weeks, macroscopic observation showed erosion of the tibial and femoral cartilage in the PBS and 95\% FBS knees (Fig. 3B). The gross finding score for both the tibial and femoral cartilage was significantly higher in the PBS knees than in the cultured MSC knees (Fig. 3C). The gross finding score in both the tibial and femoral cartilage was also significantly higher in the $95 \%$ FBS knees than in the thawed MSC knees. Histological observation revealed a decrease in staining of cartilage matrix in tibial cartilage in the PBS and 95\% FBS knees at 8 weeks (Fig. 4A). The OARSI histological score in tibial cartilage was significantly higher in the PBS knees than in the cultured MSC knees and was also significantly higher in the 95\% FBS knees than in the thawed MSC knees (Fig. 4B). The femoral cartilage did not show as obvious an effect of the two MSC groups as observed for the tibial cartilage.

\section{Comparison of the inhibitory effect of cultured versus thawed MSCs on OA progression}


We calculated the sample size for comparison between thawed MSCs and cultured MSCs using the OARSI histological score for tibial cartilage. Assuming a standard deviation of 2.5 and a correlation between the groups of 0.5 , a sample size of 8 was deemed sufficient to detect a difference of 3 calculated by $30 \%$ average difference of the OARSI histological score between the PBS and cultured MSC knees (Fig. 4B) with $80 \%$ power and $5 \%$ level of significance (two-tailed Wilcoxon singed rank test). Considering the dropout rate, we used 9 rats for the experiment. We injected cultured MSCs into the left and right sides of the knee and thawed MSCs into the contralateral knee in nine rats in the OA model and evaluated them at eight weeks (Fig. 5A). Fibrillation and erosion were seen macroscopically in the tibial cartilage on both sides, while little erosion was seen on both sides in the femoral cartilage (Fig. 5B). Histological evaluation of the tibial cartilage showed individual differences from the preserved cartilage matrix to the focal defect in each animal (Fig. 6A). The difference in OARSI histological score between MSCs was $0,-1.5-1$ (median, interquartile range) in the tibial cartilage, with no statistical significance (Fig. 6B). The femoral cartilage was less degenerated than the tibial cartilage and no significant difference was detected between the two groups.

\section{Discussion}

Both the cultured and thawed MSCs had significantly lower gross findings and histological scores for the tibial cartilage when compared with the controls without MSCs. For direct comparison of both knees in the cultured and thawed MSCs, we set the primary outcome as the histological score of the tibial cartilage and the sample number as nine. The histological scores did not differ significantly between the two groups.

Rat synovial MSCs cryopreserved in 95\% FBS with 5\% DMSO maintained their viability, colony formation, and chondrogenic abilities, whereas cells cryopreserved in 100\% FBS showed obviously reduced viability. Similar results have been reported previously for human synovial MSCs [25]. DMSO in the cryopreservation fluid substantially increased the viability of synovial MSCs. A systematic review of 41 in vitro studies of bone marrow MSCs by Bahsoun et al. showed that cryopreservation does not affect the morphology, expression of surface markers, differentiation, or proliferative potential, but the effects on viability and colony-forming capacity remain to be determined [29]. Variations in viability were mainly related to differences in the cryopreservation solutions, including the DMSO concentrations, and differences in methods used to measure viability.

The thawed MSCs and cultured MSCs showed similar luminescence intensity in cells expressing luciferase. The luminescence intensity reflects the activity of the whole cell population [30]. In addition, no difference was found between the two groups following injection into the knees of OA model rats, as the luminescence intensity decreased in a similar time-dependent manner. These results indicated that the activity of the total cell population injected into the joint decreased similarly with time for both cultured MSCs and thawed MSCs. 
Injection of cultured MSCs inhibited OA progression compared to injection with PBS alone. This result is comparable to previous results reported for the rat ACL resection model of OA [20]. Injection of thawed MSCs inhibited OA progression compared to injection with 95\% FBS plus 5\% DMSO. In the control group, the gross finding score varied from 2 to 6 points and the histological score varied from 6 to 20 points, mainly due to the individual differences among the rats. We then compared thawed MSCs and cultured MSCs in both knees to remove individual differences. We set the primary endpoint as the histological score of the tibia, which had the largest difference in scores between the PBS and the cultured MSC knees. The power analysis showed a minimum sample size of 9 .

The pooled SD and the correlation were close to the assumed value, so the expected power was maintained. No significant difference was observed in the histological score of the tibia between the knees treated with cultured or thawed MSCs. The gross finding scores of the tibia and femur were also similar. From these results, we concluded that thawed MSCs showed a comparable inhibitory effect on OA progression in rats to that observed with cultured cells. This is the first report showing an inhibitory effect of thawed synovial MSCs on OA progression. In clinical situations, weekly injections of fresh cultured MSCs need repeated cell culture and associated manpower and cost. The ability to use stocks of thawed cryopreserved MSCs would solve these problems and make weekly injections far more convenient for OA patients.

Our study had two limitations. One was that the fluids for MSC suspension differed between the cultured and thawed MSCs, as the cultured MSCs were suspended in PBS and the thawed MSCs were suspended in $95 \%$ FBS with $5 \%$ DMSO. The effects of this different composition on the experimental results are not known. A second limitation is that we cryopreserved the MSCs only for 7 days. A longer period of cryopreservation could lead to different results. However, the viability of human umbilical cord MSCs cryopreserved for 1 year was comparable to that of cells cryopreserved for 7 days [31], suggesting that the results would not change even if the synovial MSCs were cryopreserved for 1 year.

\section{Conclusion}

Thawed cryopreserved MSCs and cultured MSCs showed a comparable inhibitory effect on OA progression in a rat meniscectomized OA model.

\section{Abbreviations}

MSCs: Mesenchymal stem cells; OA: osteoarthritis; FBS: fetal bovine serum; DMSO: dimethyl sulfoxide

\section{Declarations}

\section{Ethics approval and consent to participate}

All animal care and experiments were conducted in accordance with the institutional guidelines of the Animal Committee of Tokyo Medical and Dental University. 


\section{Consent for publication}

All authors gave their consent for publication.

\section{Availability of data and materials}

The datasets obtained and analyzed in the current study are available from the corresponding author on reasonable request.

\section{Competing interests}

The authors declare that they have no competing interests.

\section{Funding}

This study was supported by the Japan Agency for Medical Research and Development (AMED) under grants JP20bk0104103.

\section{Authors' contributions}

$\mathrm{KH}$ : Conception and design. Collection and assembly of data. Data analysis and interpretation. Manuscript writing. Final approval of manuscript. NO: Conception and design. Administrative support. Data analysis and interpretation. Final approval of manuscript. KE: Administrative support. Collection and assembly of data. Data analysis and interpretation. Final approval of manuscript. MM: Conception and design. Administrative support. Collection and assembly of data. Data analysis and interpretation. Final approval of manuscript. MA: Data analysis and interpretation. Final approval of manuscript. HKa: Conception and design. Administrative support. Data analysis and interpretation. Final approval of manuscript. KT: Data analysis and interpretation. Final approval of manuscript. HKo: Data analysis and interpretation. Final approval of manuscript. IS: Conception and design. Financial support. Administrative support. Collection and assembly of data. Data analysis and interpretation. Manuscript writing. Final approval of manuscript.

\section{Acknowledgements}

We thank Ms. Mika Watanabe and Ms. Kimiko Takanashi for the management of our laboratory and Ms. Ellen Roider for English editing.

\section{Author's information}

1 Center for Stem Cell and Regenerative Medicine, Tokyo Medical and Dental University, Tokyo, Japan. 2 Research Administration Division, Tokyo Medical and Dental University, Tokyo, Japan. 3 Department of Cartilage Regeneration, Tokyo Medical and Dental University, Tokyo, Japan. 4 Department of Joint Surgery and Sports Medicine, Tokyo Medical and Dental University, Tokyo, Japan. 


\section{References}

1. Arden N, Nevitt MC. Osteoarthritis: epidemiology. Best Pract Res Clin Rheumatol. 2006;20(1):3-25. doi:10.1016/j.berh.2005.09.007.

2. Neogi T. The epidemiology and impact of pain in osteoarthritis. Osteoarthritis Cartilage. 2013;21(9):1145-53. doi:10.1016/j.joca.2013.03.018.

3. Palazzo C, Ravaud JF, Papelard A, Ravaud P, Poiraudeau S. The burden of musculoskeletal conditions. PLoS One. 2014;9(3):e90633. doi:10.1371/journal.pone.0090633.

4. Doyle EC, Wragg NM, Wilson SL. Intraarticular injection of bone marrow-derived mesenchymal stem cells enhances regeneration in knee osteoarthritis. Knee Surg Sports Traumatol Arthrosc. 2020. doi:10.1007/s00167-020-05859-z.

5. Emadedin M, Aghdami N, Taghiyar L, Fazeli R, Moghadasali R, Jahangir S et al. Intra-articular injection of autologous mesenchymal stem cells in six patients with knee osteoarthritis. Arch Iran Med. 2012;15(7):422-8. doi:012157/AIM.0010.

6. Orozco L, Munar A, Soler R, Alberca M, Soler F, Huguet M et al. Treatment of knee osteoarthritis with autologous mesenchymal stem cells: a pilot study. Transplantation. 2013;95(12):1535-41. doi:10.1097/TP.0b013e318291a2da.

7. Vega A, Martin-Ferrero MA, Del Canto F, Alberca M, Garcia V, Munar A, et al. Treatment of knee osteoarthritis with allogeneic bone marrow mesenchymal stem cells: a randomized controlled trial. Transplantation. 2015;99(8):1681-90. doi:10.1097/TP.0000000000000678.

8. Yokota N, Hattori M, Ohtsuru T, Otsuji M, Lyman S, Shimomura K, et al. Comparative clinical outcomes after intra-articular injection with adipose-derived cultured stem cells or noncultured stromal vascular fraction for the treatment of knee osteoarthritis. Am J Sports Med. 2019;47(11):2577-83. doi:10.1177/0363546519864359.

9. Chinnadurai R, Garcia MA, Sakurai Y, Lam WA, Kirk AD, Galipeau J et al. Actin cytoskeletal disruption following cryopreservation alters the biodistribution of human mesenchymal stromal cells in vivo. Stem Cell Reports. 2014;3(1):60-72. doi:10.1016/j.stemcr.2014.05.003.

10. Lauterboeck L, Saha D, Chatterjee A, Hofmann N, Glasmacher B. Xeno- free cryopreservation of bone marrow-derived multipotent stromal cells from Callithrix jacchus. Biopreserv Biobank. 2016;14(6):530-8. doi:10.1089/bio.2016.0038.

11. Lechanteur C, Briquet A, Giet O, Delloye O, Baudoux E, Beguin Y. Clinical-scale expansion of mesenchymal stromal cells: a large banking experience. J Transl Med. 2016;14(1):145. doi:10.1186/s12967-016-0892-y.

12. Heino TJ, Alm JJ, Moritz N, Aro HT. Comparison of the osteogenic capacity of minipig and human bone marrow-derived mesenchymal stem cells. J Orthop Res. 2012;30(7):1019-25. doi:10.1002/jor.22049.

13. Bruder SP, Jaiswal N, Haynesworth SE. Growth kinetics, self-renewal, and the osteogenic potential of purified human mesenchymal stem cells during extensive subcultivation and following 
cryopreservation. J Cell Biochem. 1997;64(2):278-94. doi:10.1002/(sici)10974644(199702)64:2<278::aid-jcb11>3.0.co;2-f.

14. Ginis I, Grinblat B, Shirvan MH. Evaluation of bone marrow-derived mesenchymal stem cells after cryopreservation and hypothermic storage in clinically safe medium. Tissue Eng Part C Methods. 2012;18(6):453-63. doi:10.1089/ten.TEC.2011.0395.

15. Matsumura K, Hayashi F, Nagashima T, Hyon SH. Long-term cryopreservation of human mesenchymal stem cells using carboxylated poly-l-lysine without the addition of proteins or dimethyl sulfoxide. J Biomater Sci Polym Ed. 2013;24(12):1484-97. doi:10.1080/09205063.2013.771318.

16. Mamidi MK, Nathan KG, Singh G, Thrichelvam ST, Mohd Yusof NA, Fakharuzi NA et al. Comparative cellular and molecular analyses of pooled bone marrow multipotent mesenchymal stromal cells during continuous passaging and after successive cryopreservation. J Cell Biochem. 2012;113(10):3153-64. doi:10.1002/jcb.24193.

17. Tan Y, Salkhordeh M, Wang JP, McRae A, Souza-Moreira L, Mclntyre L, et al. Thawed mesenchymal stem cell product shows comparable immunomodulatory potency to cultured cells in vitro and in polymicrobial septic animals. Sci Rep. 2019;9(1):18078. doi:10.1038/s41598-019-54462-x.

18. Luetzkendorf J, Nerger K, Hering J, Moegel A, Hoffmann K, Hoefers C et al. Cryopreservation does not alter main characteristics of Good Manufacturing Process-grade human multipotent mesenchymal stromal cells including immunomodulating potential and lack of malignant transformation. Cytotherapy. 2015;17(2):186-98. doi:10.1016/j.jcyt.2014.10.018.

19. Cruz FF, Borg ZD, Goodwin M, Sokocevic D, Wagner D, McKenna DH et al. Freshly thawed and continuously cultured human bone marrow-derived mesenchymal stromal cells comparably ameliorate allergic airways inflammation in immunocompetent mice. Stem Cells Transl Med. 2015;4(6):615-24. doi:10.5966/sctm.2014-0268.

20. Ozeki N, Muneta T, Koga H, Nakagawa Y, Mizuno M, Tsuji K, et al. Not single but periodic injections of synovial mesenchymal stem cells maintain viable cells in knees and inhibit osteoarthritis progression in rats. Osteoarthr Cartilage. 2016;24(6):1061-70. doi:10.1016/j.joca.2015.12.018.

21. Zhang R, Ma J, Han J, Zhang W, Ma J. Mesenchymal stem cell related therapies for cartilage lesions and osteoarthritis. Am J Transl Res. 2019;11(10):6275-89.

22. Horie M, Sekiya I, Muneta T, Ichinose S, Matsumoto K, Saito H et al. Intra-articular Injected synovial stem cells differentiate into meniscal cells directly and promote meniscal regeneration without mobilization to distant organs in rat massive meniscal defect. Stem Cells. 2009;27(4):878-87. doi:10.1634/stemcells.2008-0616.

23. Yoshimura H, Muneta T, Nimura A, Yokoyama A, Koga H, Sekiya I. Comparison of rat mesenchymal stem cells derived from bone marrow, synovium, periosteum, adipose tissue, and muscle. Cell Tissue Res. 2007;327(3):449-62. doi:10.1007/s00441-006-0308-z.

24. Okuno M, Muneta T, Koga H, Ozeki N, Nakagawa $Y$, Tsuji K et al. Meniscus regeneration by syngeneic, minor mismatched, and major mismatched transplantation of synovial mesenchymal stem cells in a rat model. J Orthop Res. 2014;32(7):928-36. doi:10.1002/jor.22614. 
25. Fujisawa R, Mizuno M, Katano H, Otabe K, Ozeki N, Tsuji K et al. Cryopreservation in $95 \%$ serum with $5 \%$ DMSO maintains colony formation and chondrogenic abilities in human synovial mesenchymal stem cells. BMC Musculoskelet Disord. 2019;20(1):316. doi:10.1186/s12891-019-2700-3.

26. Shioda M, Muneta T, Tsuji K, Mizuno M, Komori K, Koga H et al. TNFalpha promotes proliferation of human synovial MSCs while maintaining chondrogenic potential. PLoS One. 2017;12(5):e0177771. doi:10.1371/journal.pone.0177771.

27. Yanagisawa K, Muneta T, Ozeki N, Nakagawa Y, Udo M, Saito R et al. Weekly injections of Hylan G-F 20 delay cartilage degeneration in partial meniscectomized rat knees. BMC Musculoskelet Disord. 2016;17:188. doi:10.1186/s12891-016-1051-6.

28. Pritzker KP, Gay S, Jimenez SA, Ostergaard K, Pelletier JP, Revell PA, et al. Osteoarthritis cartilage histopathology: grading and staging. Osteoarthr Cartilage. 2006;14(1):13-29. doi:10.1016/j.joca.2005.07.014.

29. Bahsoun S, Coopman K, Akam EC. The impact of cryopreservation on bone marrow-derived mesenchymal stem cells: a systematic review. J Transl Med. 2019;17(1):397. doi:10.1186/s12967019-02136-7.

30. Kasahara N, Kikuchi T, Doi J, Teratani T, Fujimoto Y, Uemoto S et al. Luminescence-based assay to screen preservation solutions for optimal ability to maintain viability of rat intestinal grafts. Transplant Proc. 2013;45(6):2486-90. doi:10.1016/j.transproceed.2013.02.117.

31. Kim S-M, Yun C-K, Park J-H, Hwang JW, Kim Z-H, Choi Y-S. Efficient cryopreservation of human mesenchymal stem cells using silkworm hemolymph-derived proteins. J Tissue Eng Regen Med. 2017;11(8):2181-92. doi:10.1002/term.2116.

\section{Figures}


Figure 1
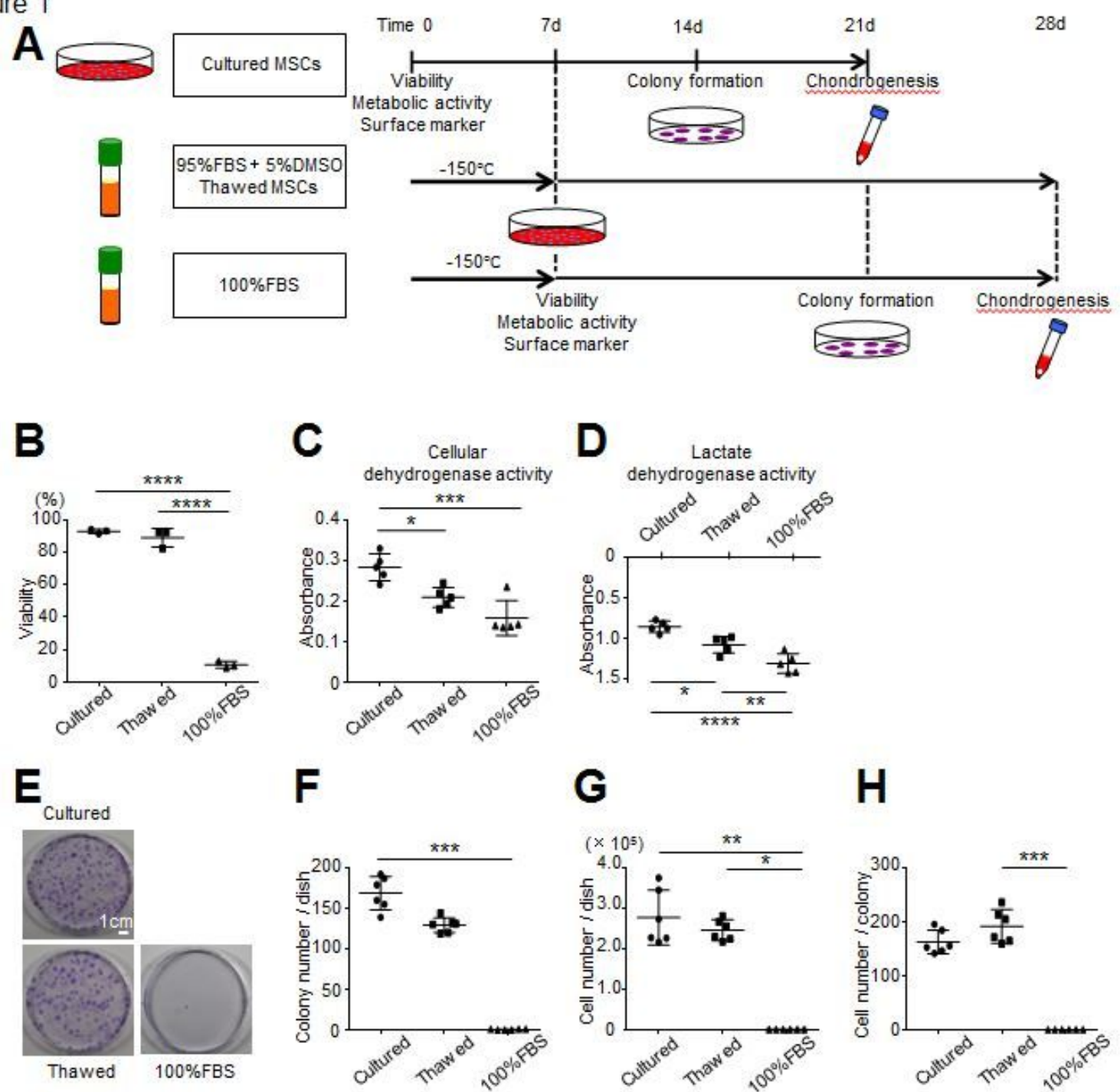

H
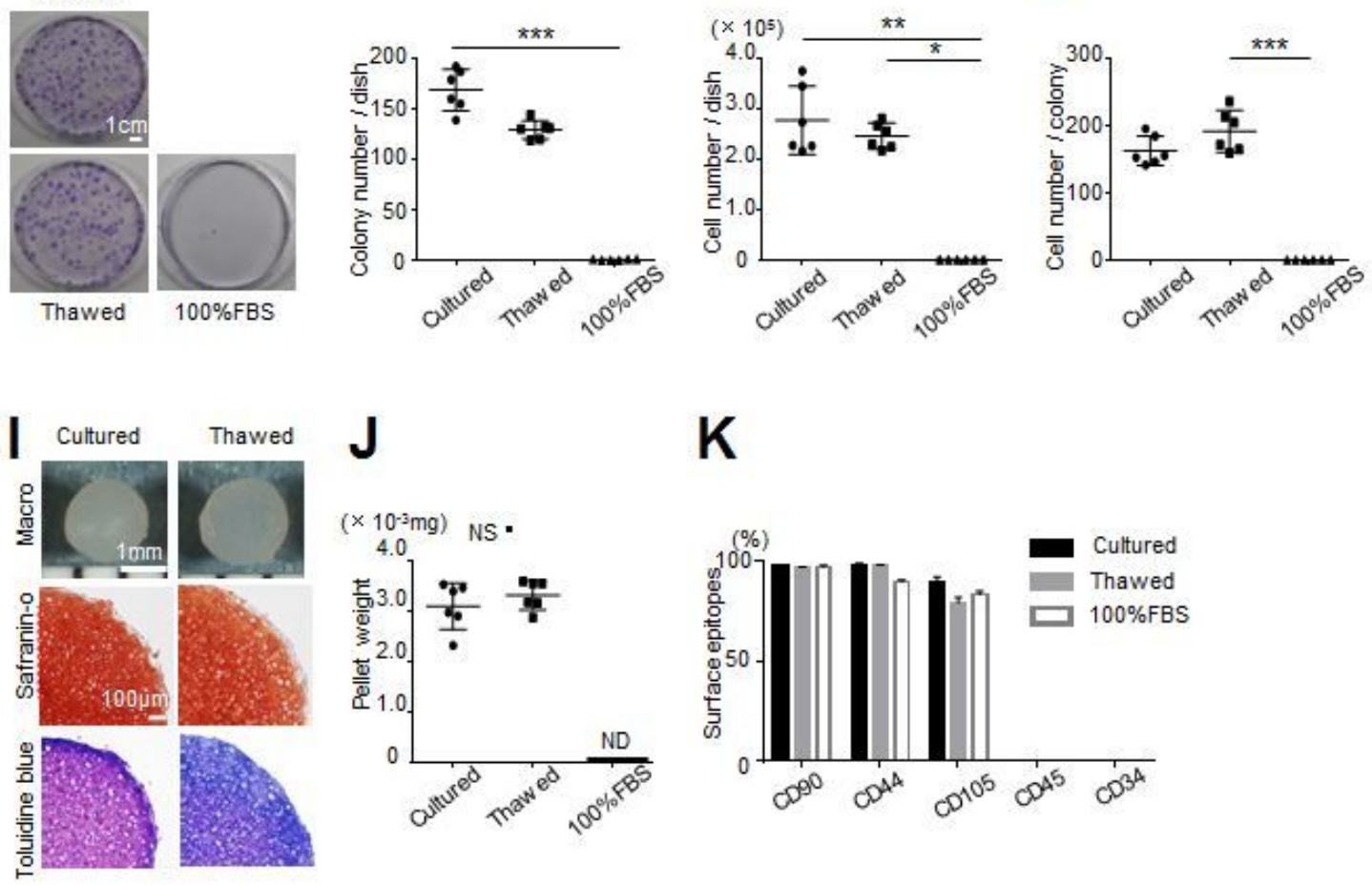

\section{Figure 1}

Effects of cryopreservation on the in vitro viability and properties of rat synovial MSCs. (A) Scheme: $1 \times$ 106 synovial MSCs were suspended in $1000 \mu \mathrm{L}$ PBS as cultured MSCs. A sample of $1 \times 106$ synovial MSCs suspended in $1000 \mu \mathrm{L}$ preservation fluid containing 95\% FBS with 5\% DMSO or 100\% FBS was cryopreserved at $-150{ }^{\circ} \mathrm{C}$ for 7 days for use as thawed MSCs or negative controls. The cells were analyzed for viability, metabolic activity, and surface markers. A $0.5 \mu \mathrm{L}$ volume of cell suspension 
(containing 500 cells, including living and dead cells) was allocated to a $60 \mathrm{~cm} 2$ dish and cultured for colony formation. A $250 \mu \mathrm{L}$ volume of cell suspension (containing $2.5 \times 105$ cells, including living and dead cells) was allocated to a $15 \mathrm{~mL}$ tube and cultured for chondrogenesis. (B) Viability assessed by trypan blue staining. The average with $S D$ is shown $(n=3)$. (C) Cellular dehydrogenase activity was used to confirm live cell metabolic activity $(n=5)$. (D) Lactate dehydrogenase activity was used as a marker of dead cells $(n=5)$. (E) Colony formation: colonies were stained with crystal violet. $(F)$ Colony number per dish $(n=6)$. (G) Cell number per dish $(n=6)$. (H) Cell number per colony $(n=6)$. (I) Cartilage pellets and histological images. (J) Cartilage pellet weight $(n=6)$. (K) Surface epitopes $(n=3)$. ND, not detected; NS, not significant; ${ }^{*} p<0.05,{ }^{\star \star} p<0.01,{ }^{\star \star *} p<0.001$, ${ }^{\star \star \star \star} p<0.0001$ by repeated measures one-way ANOVA followed by Tukey's multiple comparisons (Fig. 1B, C, and D), Kruskal-Wallis test followed by Dunn's multiple comparisons (Fig. 1F, G, and H) or Student's t-test between two unpaired groups (Fig. 1J).

Figure 2
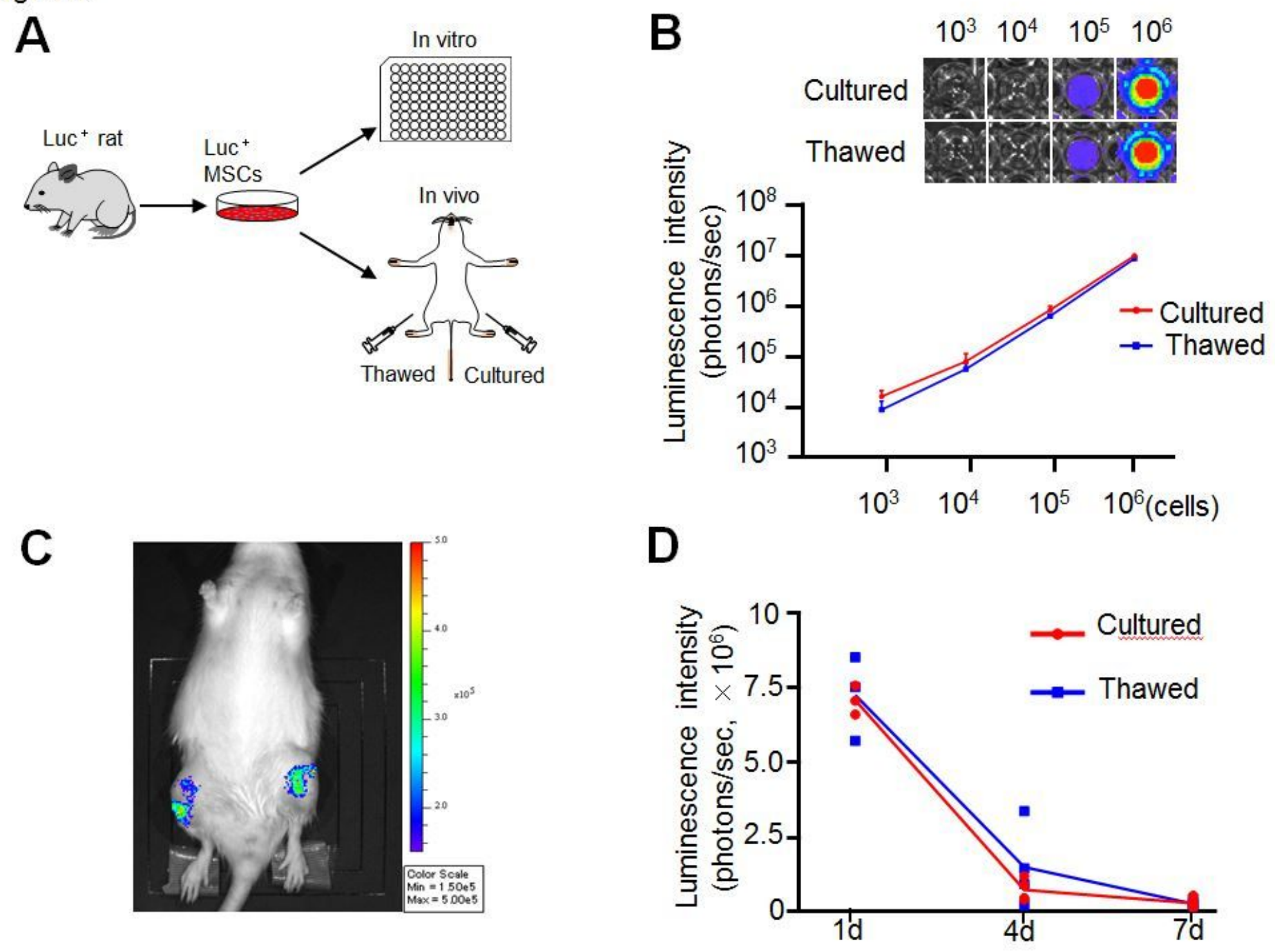

Figure 2

In vitro and in vivo bioluminescence imaging analysis. (A) Scheme: Synovial MSCs were derived from luciferase-expressing transgenic rats. Cultured MSCs and thawed croypreserved MSCs were plated into 
96-well plates and then used for injection into the knees. (B) In vitro luminescence images and intensity. Synovial MSCs derived from luciferase-expressing transgenic rat MSCs were allocated into samples of $103,104,105$, and 106 cells and assessed. The average with SD is shown $(n=3)$. (C) In vivo

bioluminescence imaging analysis. The anterior half of the MM in both knees of each rat was removed, 106 cultured MSCs were injected into one knee and 106 thawed cryopreserved MSCs were injected into the contralateral knee without compensation for viability. The scheme and representative images at 1 day are shown. (D) Luminescence intensity. The average is shown as a line graph. 1 day $(n=3)$, and 4 and 7 days $(n=4)$.

Figure 3

A

Surgery Injection

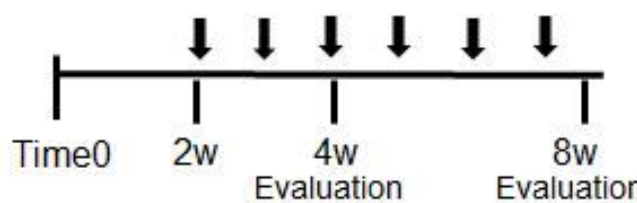

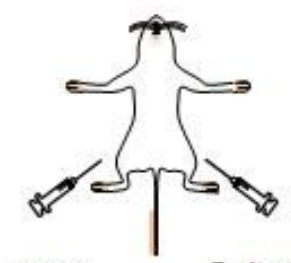

PBS

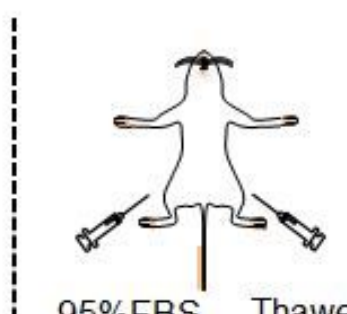

95\%FBS Thawed

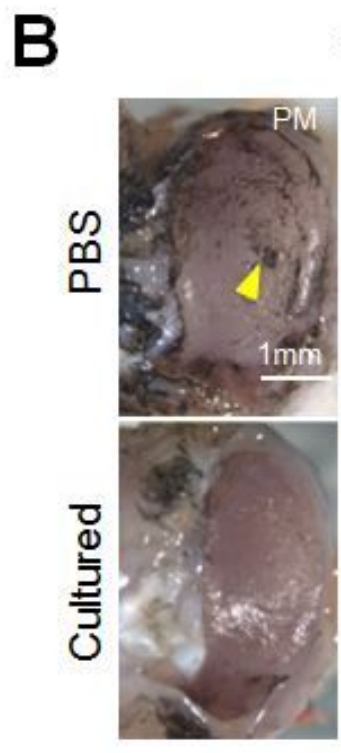

Tibia

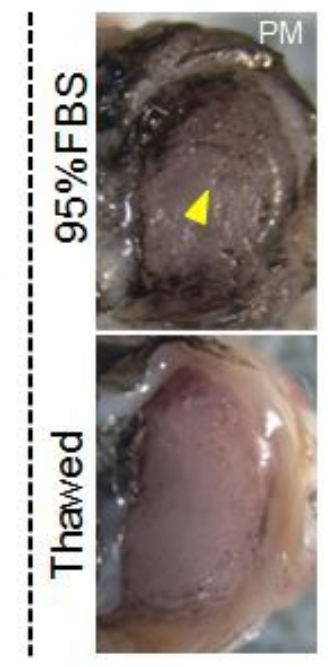

C

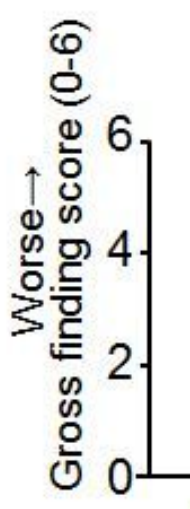

Tibia
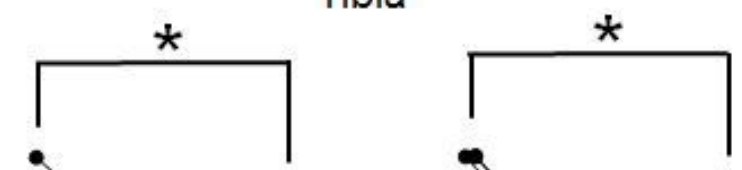

Femur
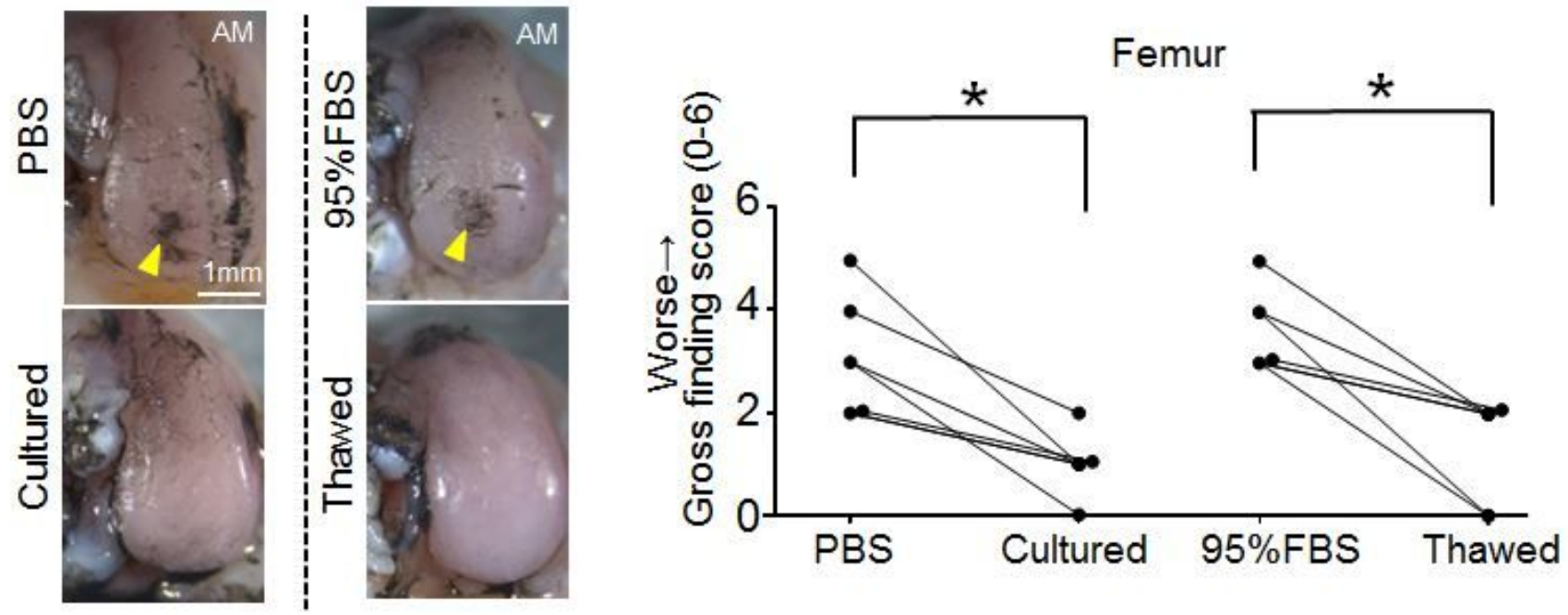


\section{Figure 3}

Macroscopic analysis of the inhibitory effect of cultured MSCs versus thawed cryopreserved MSCs on osteoarthritis (OA) progression in rats. (A) Scheme. For the rat OA model, PBS was injected into the knee and 106 cultured MSCs suspended in PBS were injected into contralateral knee every week from two weeks. Also, 95\% FBS with 5\% DMSO was injected into the knee and 106 thawed MSCs suspended in 95\% FBS with 5\% DMSO without compensation with viability were injected into contralateral knee every week from two weeks. The knee cartilage was assessed to compare the left and right sides of the same individual at 4 weeks (Supplementary Figure 1,2) and 8 weeks. (B) Representative macroscopic images for medial tibial and femoral condyles stained with India ink. The images in cultured and thawed groups are inverted horizontally for ease of comparison. Yellow arrow head indicates cartilage erosion. PM, posteromedial; AM, anteromedial. (C) Gross finding score. ${ }^{\star} p<0.05$ by Wilcoxon's signed rank test $(n=6)$. 
Figure 4

A

Tibia
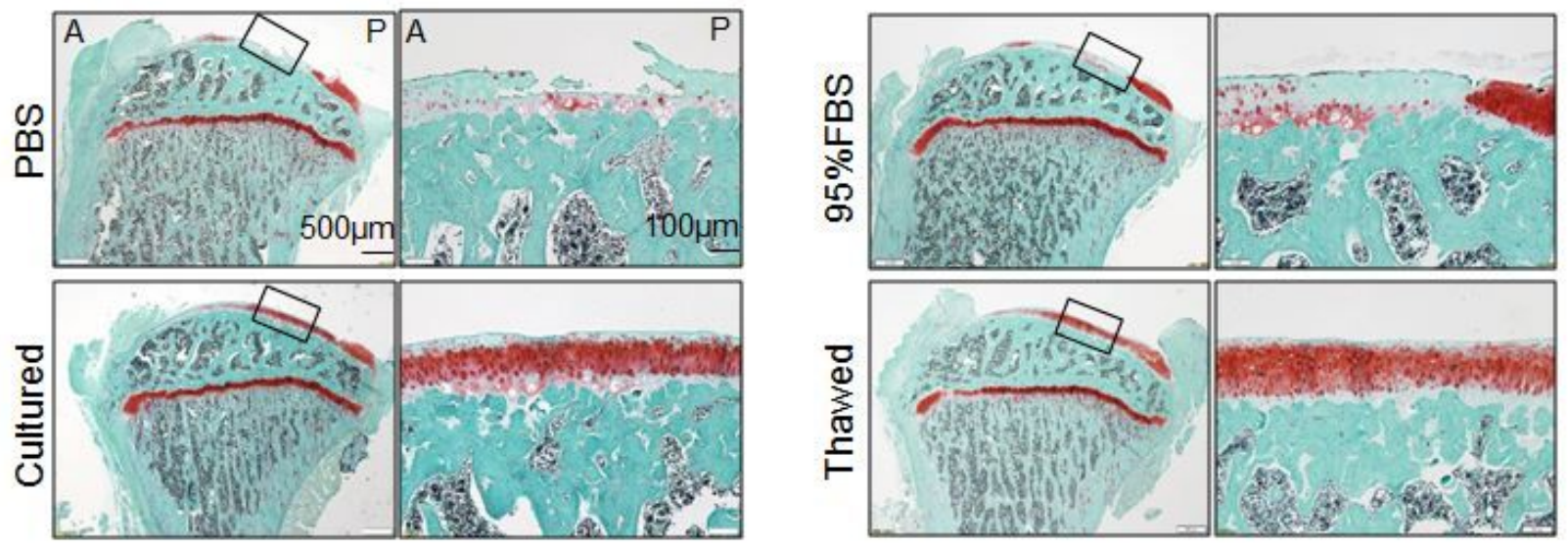

Femur
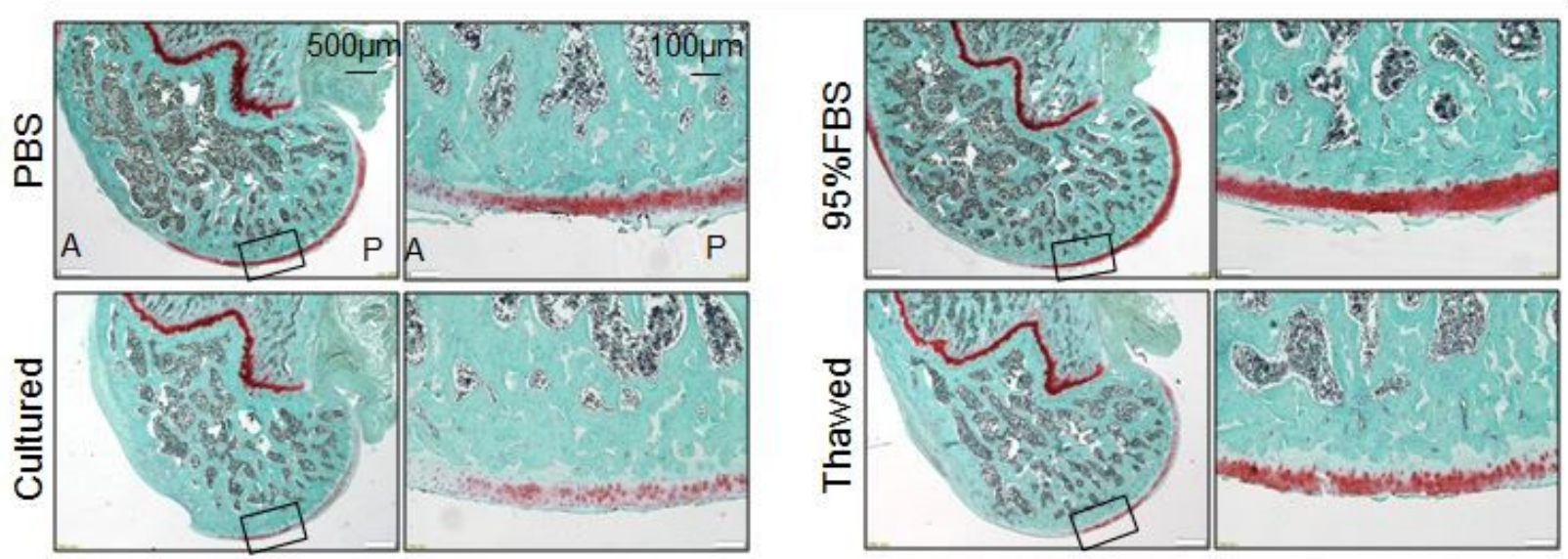

B

Tibia
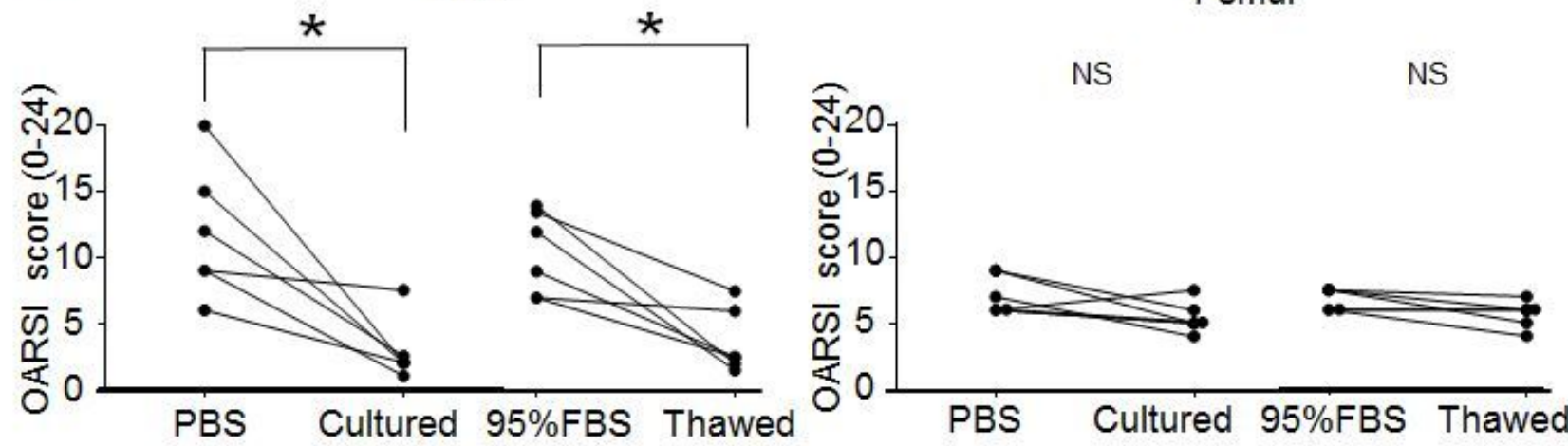

\section{Figure 4}

Histological analysis of the inhibitory effect of cultured MSCs versus thawed cryopreserved MSCs on osteoarthritis (OA) progression. (A) Representative histological sections stained with safranin-o. A, anterior; P, posterior. (B) Osteoarthritis Research Society International (OARSI) histological score. NS, not significant; ${ }^{*} p<0.05$ by Wilcoxon's signed rank test $(n=6)$. 
Figure 5

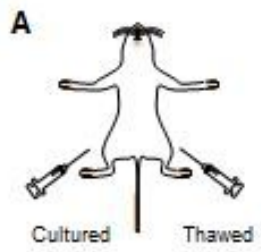

B
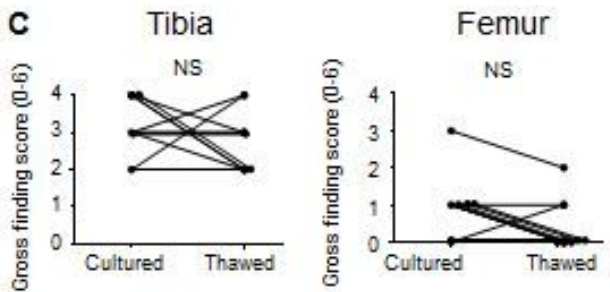

Tibia
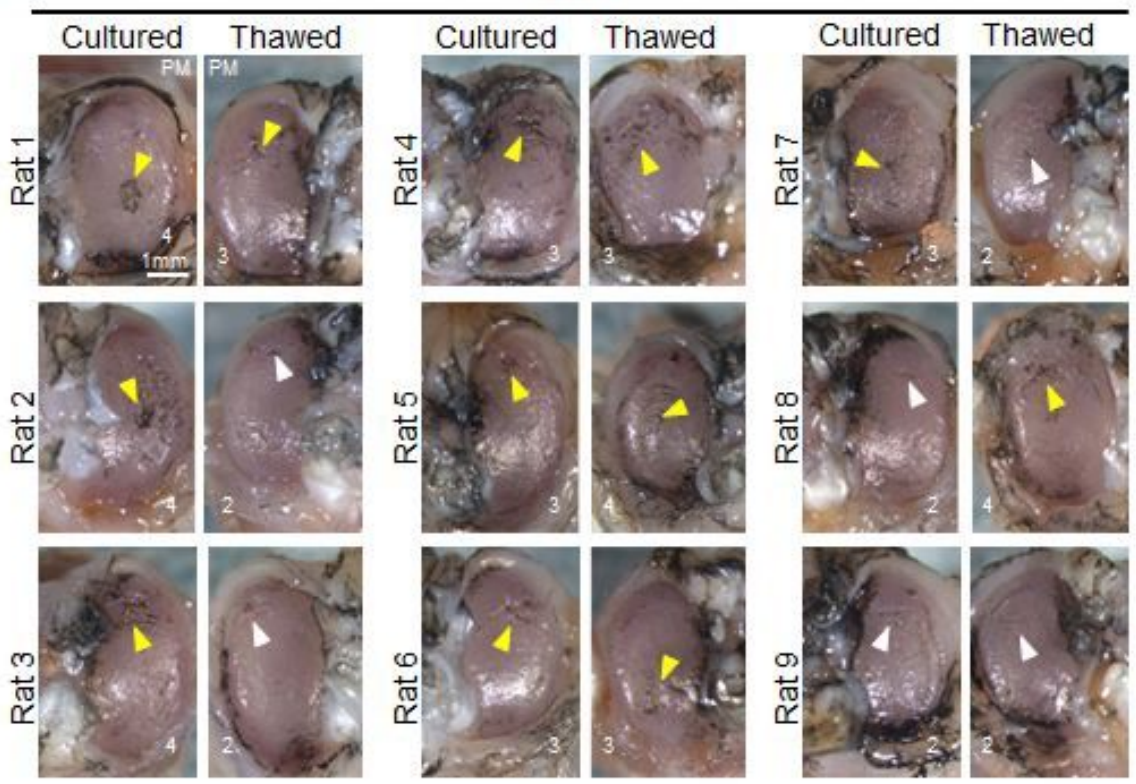

Femur
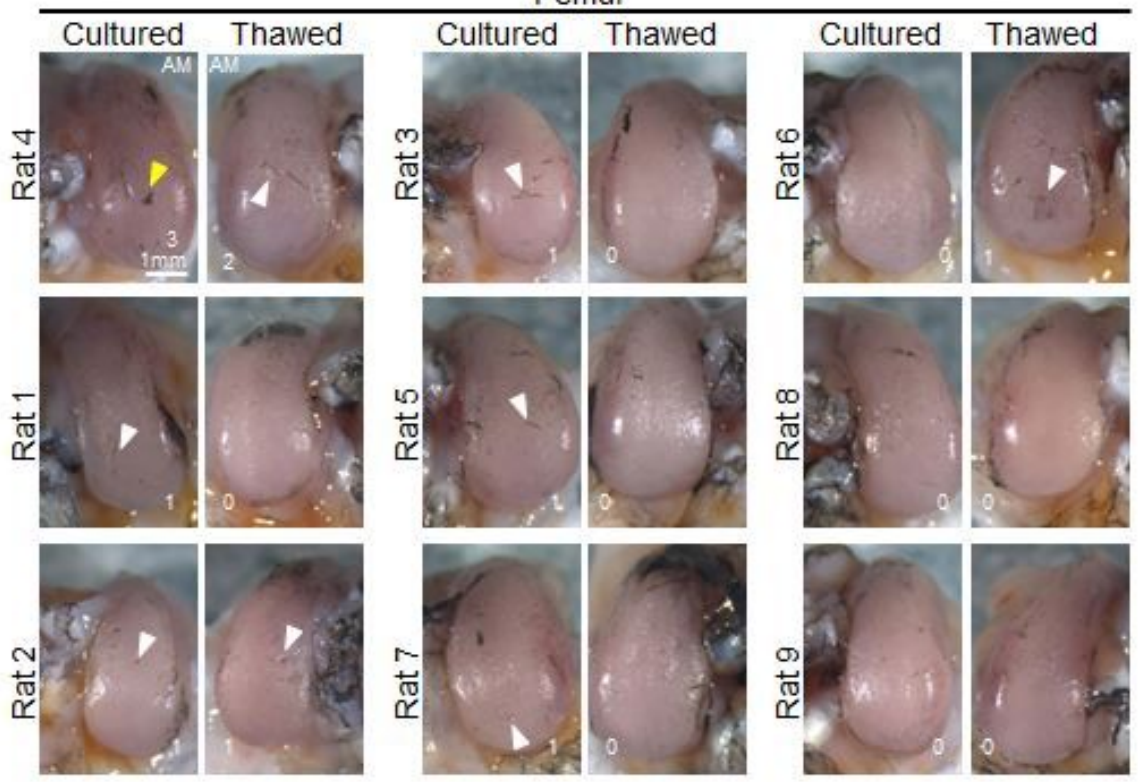

\section{Figure 5}

Macroscopic comparison of the inhibitory effects of cultured MSCs versus thawed cryopreserved MSCs on OA progression in both knees of the same rat. (A) Scheme: Rat OA models were treated with cultured MSCs and thawed cryopreserved MSCs. Cultured MSCs were injected into one knee and thawed MSCs were injected into the contralateral knee every week two weeks after the surgery. The knee cartilage was assessed by comparing the left and right knees of the same rat at 8 weeks. (B) Macroscopic images of 
the medial tibial and femoral condyles stained with India ink. All images are shown with gross finding scores. White arrowhead indicates fibrillation and yellow arrowhead indicates cartilage erosion. The images in the cultured cell and thawed cell groups are inverted horizontally for ease of comparison. Images are arranged in the order of the worst gross finding scores on the cultured side. PM, posteromedial; AM, anteromedial. (C) Gross finding score. NS, not significant by Wilcoxon's signed rank test $(n=9)$.

Figure 6 A

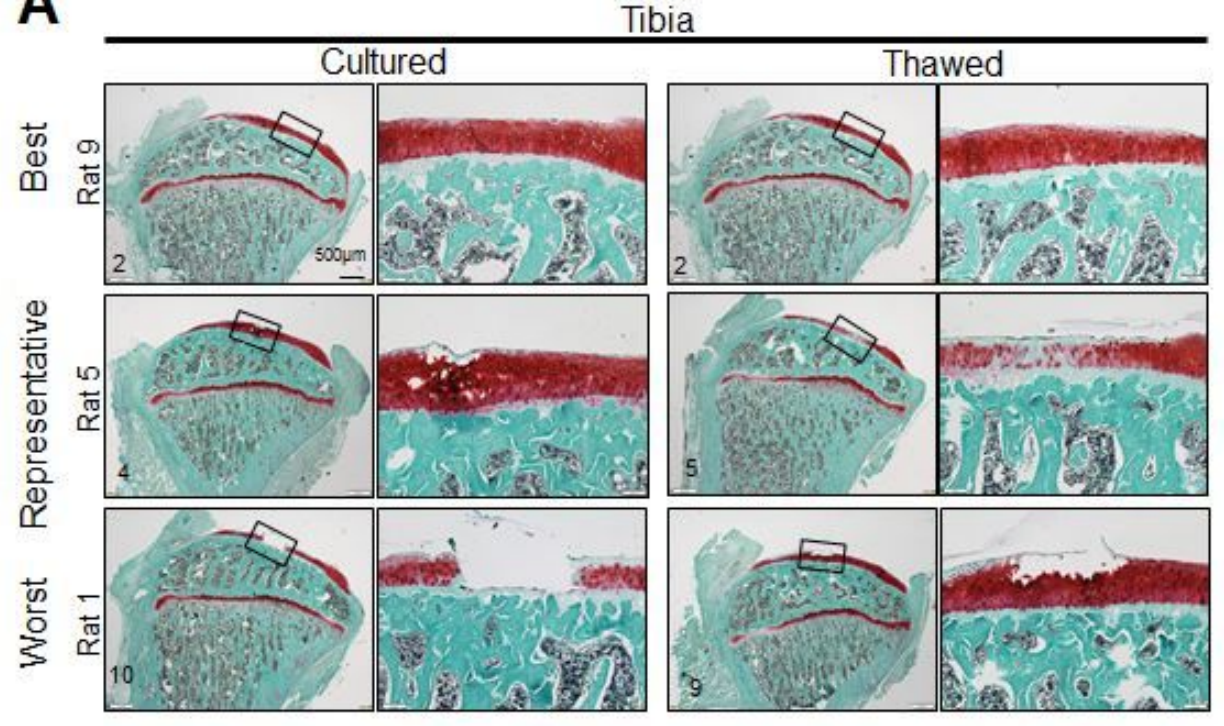

Femur

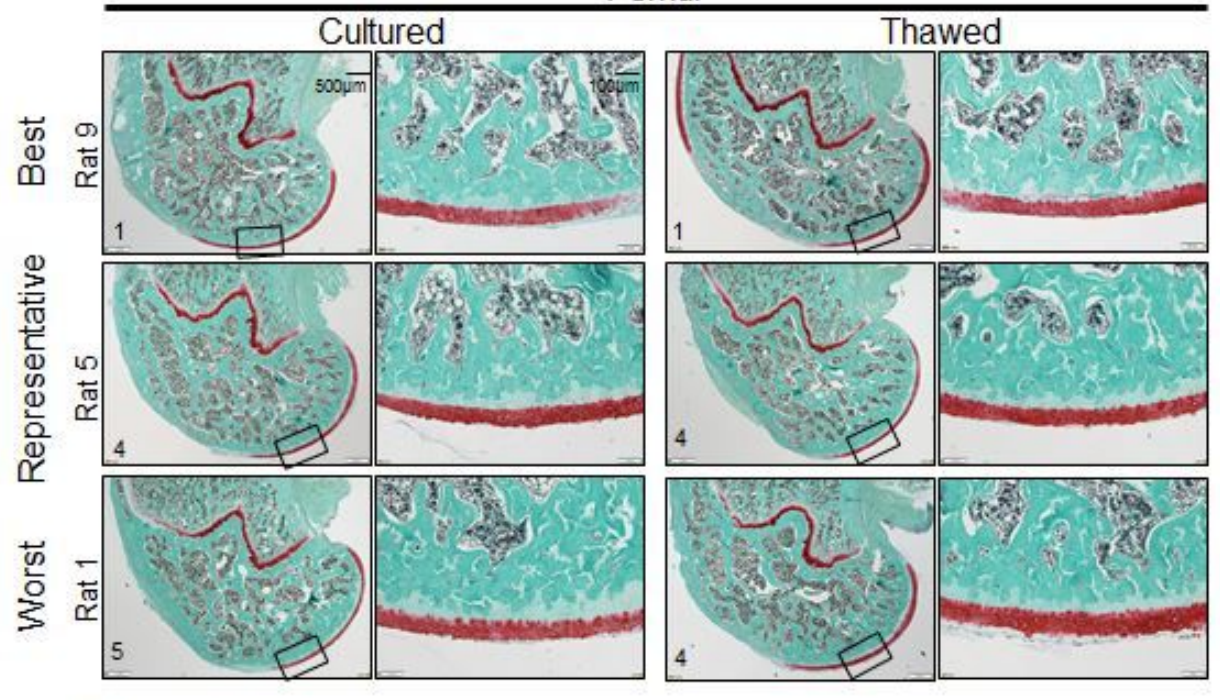

B
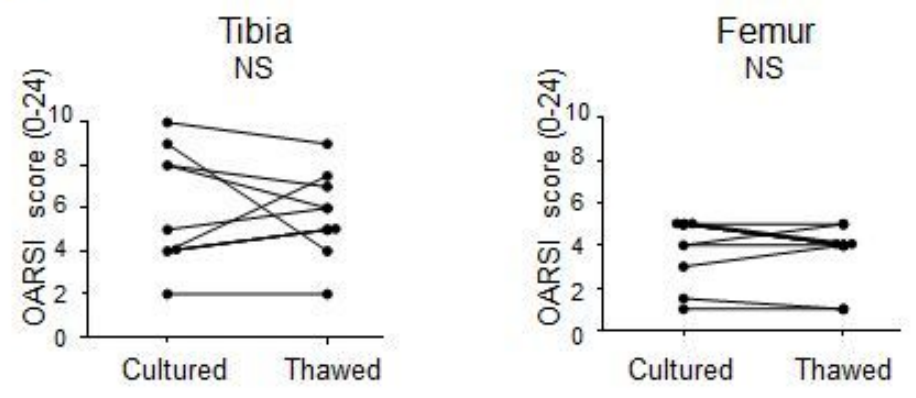

Figure 6 
Histological comparison of the inhibitory effects of cultured MSCs versus thawed cryopreserved MSCs on OA progression in both knees of the same rat. (A) Histological images for medial tibial and femoral condyles stained with safranin 0 . Best, representative, and worst images are selected based on Osteoarthritis Research Society International (OARSI) histological scores on the cultured cell side. (B) Statistical analysis of OARSI histological score. NS, not significant by Wilcoxon's signed rank test $(n=9)$.

\section{Supplementary Files}

This is a list of supplementary files associated with this preprint. Click to download.

- Horiuchifiguresupplementary.pptx 